\title{
Estudo taxonômico do gênero Abuta (Menispermaceae) no Estado do Pará, Brasil
}

\author{
Julio dos Santos de SOUSA ${ }^{1 *}$, Maria de Nazaré do Carmo BASTOS ${ }^{1}$, Ely Simone Cajueiro GURGEL ${ }^{1}$ \\ Museu Paraense Emílio Goeldi - MCT, Campus de Pesquisa, Coordenação de Botânica. Av. Perimetral, 1901, Terra Firme, Belém-PA, CEP. 66017-970, Fone: (91) $3217-6073$. \\ jssousa27@yahoo.com.br, nazir@museu-goeldi.br, esgurgel@museu-goeldi.br. \\ Autor Correspondente: jssousa27@yahoo.com.br.
}

\section{RESUMO}

Abuta é um gênero taxonomicamente complexo devido à sobreposição de variação dos caracteres morfológicos. O presente estudo consiste no tratamento taxonômico de Abuta no Estado do Pará. A análise envolveu amostras provenientes de coletas e exsicatas dos herbários Museu Goeldi (MG), Instituto Agronômico do Norte (IAN), Instituto Nacional de Pesquisas da Amazonia (INPA), Jardim Botânico do Rio de Janeiro (RB) e New York Botanical Garden (NY). São apresentados chave de identificação, descrições, distribuição geográfica, comentários e ilustrações das espécies. O gênero está representado na área por 11 espécies: A. barbata, A. brevifolia, A. candollei, A. grandifolia, A. grisebachii, A. imene, A. obovata, A. rufescens, A. sandwithiana, $A$. solimoesensis e $A$. velutina. Abuta obovata e $A$. velutina são novos registros para o estado do Pará. A venação foliar foi o principal caractere para a separação das espécies e a formação de capoeira o ecossistema que apresentou o maior número de espécies.

PALAVRAS-CHAVE: Amazônia, Anomospermeae, botânica, morfologia, taxonomia.

\section{The taxonomic study of the Abuta genus (Menispermaceae) in the State of Pará, Brazil}

\section{ABSTRACT}

Abuta is a genus taxonomically complex due overlapping of morphological character variation. This study deals with the taxonomic treatment of the Abuta genus in the Pará state. The study includes the analysis of botanical material originated from new collections and specimens from the herbaria Museum Goeldi (MG), Agronomic Institute of the North (IAN), National Institute for Research in the Amazon (INPA), Rio de Janeiro Botanic Garden (RB) and New York Botanical Garden (NY). Identification key, descriptions, geographical distribution, comments, and illustrations of species are provided. In Pará the genus is represented by 11 species: A. barbata, A. brevifolia, A. candollei, A. grandifolia, A. grisebachii, A. imene, A. obovata, A. rufescens, A. sandwithiana, A. solimoesensis and A. velutina. Abuta obovata and A. velutina are new records for Pará state. The leaf venation was the main character for separating species and the secondary vegetation formation the ecosystem with the largest number of species.

KEYWORDS: Amazonia, Anomospermeae, botany, morphology, taxonomy. 


\section{INTRODUÇÃO}

Menispermaceae Juss. está inserida na ordem Ranunculales, com cerca de 70 gêneros e 450-500 espécies, apresentando distribuição essencialmente pantropical (Ortiz et al. 2007; Hoot et al. 2009). No Brasil, a família compreende 16 gêneros, 110 espécies (26 endêmicas), seis subespécies e sete variedades (Braga 2012; Forzza et al. 2010), sendo Abuta Aubl. um dos gêneros mais representativo da família.

Abuta foi descrito por Aublet e está constituído por cerca de 35 espécies tropicais (Di Stasi e Hiruma-Lima 2002). Ocorre nas florestas tropicais, do sul do México a Bolívia, passando pelo Brasil, tendo maior diversidade na Amazônia (incluindo a extra brasileira), Guiana, Suriname e Guiana Francesa (Barneby 2001). Os representantes deste grupo destacam-se tanto pelo hábito do tipo liana da maioria das espécies, como pela importância medicinal, pois segundo Sothers et al. (1999), muitas espécies são ricas em alcaloides, cujas folhas, cascas, madeiras e raízes têm utilidades medicinais para várias moléstias, são usadas também na preparaçáo do "curare", nas pontas de flechas e como venenos para peixes.

Trata-se de um gênero morfologicamente complexo e pouco estudado em nível taxonômico, principalmente no Brasil, em que está representado em floras regionais ou locais, destacando-se os tratamentos de Albuquerque (1972), que estudou a nervaçáo foliar de cinco espécies de Abuta, Sothers et al. (1999), que registraram sete espécies do gênero na Reserva Ducke e Krukoff (1982), que discorreu notas suplementares das espécies de Abuta (Anomospermeae) para América.

Diante disso, o presente trabalho teve por objetivo realizar o estudo taxonômico de Abuta no estado do Pará, propiciando avanço para o conhecimento do gênero na flora do Brasil.

\section{MATERIAL E MÉTODOS}

O estudo foi baseado em material herborizado, proveniente do estado do Pará, incorporado aos herbários do Museu Paraense Emílio Goeldi (MG); Embrapa Amazônia Oriental (IAN), Instituto Nacional de Pesquisas da Amazônia (INPA), Jardim Botânico do Rio de Janeiro (RB) e New York Botanical Garden (NY), além de amostras coletadas nos municípios de Barcarena, Belém, Castanhal, Marabá, Marapanim, Moju, Nova Timboteua e distrito de Mosqueiro, no período de agosto de 2010 a março de 2012. Para as etapas de coleta foram adotadas as recomendaçôes técnicas propostas por Fidalgo e Bononi (1984). O material foi analisado com auxílio de estereomicroscópio com câmara-clara acoplada, de acordo com a metodologia clássica utilizada em taxonomia vegetal, adotando-se as terminologias das partes vegetativas e reprodutivas de acordo com Hickey (1973), Rizzini (1977) e Gonçalves e Lorenzi (2007). As descrições das espécies foram baseadas nas coleçôes herborizadas identificadas por especialistas, com o suporte das diagnoses e de literatura especializada, que serviram também para a identificação dos táxons. As ilustraçôes foram feitas pelos autores utilizando-se a técnica de nanquim sobre papel vegetal, à mão livre. As siglas dos herbários estão de acordo com Thiers (2012).

\section{RESULTADOS}

Abuta Aubl., Hist. Pl. Guiane1: 618, pl. 250. 1775.

Arbustos ou lianas lenhosas 7-38 cm diâmetro., dióicos; ritidoma marrom a acinzentado, fissurado ou sulcado. Folhas simples, alternas, estípulas ausentes; venação acródroma basal, actinódroma basal ou supra-basal, nervuras principais 3-5, palmatinérveas, pseudopalmatinérveas ou plinérveas na base. Pecíolo cilíndrico ou canaliculado, com pulvino no ápice e na base. Inflorescências em racemos ou panículas, multifloras, axilares ou supra-axilares. Flores unissexuadas, actinomorfas, hipóginas; sépalas 6-9, dispostas em verticilos bisseriados ou trisseriados; pétalas ausentes. Flores estaminadas com 6 estames livres ou conados; anteras dorsifixas, com deiscência longitudinal ou transversal, bitecas. Flores pistiladas com 6 estaminódios; gineceu tricarpelar, apocárpico; ovário séssil, súpero, unilocular; óvulos 2 por carpelo, sendo 1 abortivo. Frutos drupáceos, solitários ou aos pares na infrutescência; cicatriz do estigma sub-basal, exocarpo coriáceo, mesocarpo carnoso ou escasso, endosperma ruminado.

Espécie-tipo: Abuta rufescens Aubl. Guiana Francesa. Aublet s. n. (BM)

\section{Chave para identificação das espécies de Abuta ocorrentes no estado do Pará.}

1. Venaçáo actinódroma basal. . .2

1.Venação actinódroma suprabrasal ou acródoma basal..7

2. Nervuras principais 3- palmatinérveas ou pseudopalmati

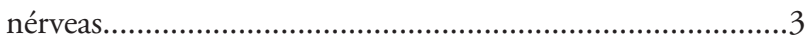

2. Nervuras principais 5-palmatinérveas..........6

3. Arbusto; alburno amarelo-escuro; estames obclavados, oblanceolados ou flusiformes. A. sandwithiana

3. Liana; alburno creme a alarajando; estames oblongos, clavados, tortuosos, lineares, turbinados ou dolabriformes................ 4

4. Lâmina foliar pubescente ou viloso-ferrugínea na face abaxial, ápice obtuso, arredondado ou emarginado...........................

4. Lâmina foliar tomentosa na face abaxial, ápice agudo a ac uminado. A. candollei

5. Pecíolo viloso-ferrugíneo; lâmina foliar cartácea; nervuras secundárias divergindo do terço inferior laminar; brácteas lanceoladas ou oblongas.

A. barbata

5. Pecíolo pubescente; lâmina foliar coriácea; nervuras secundárias divergindo da regiáo mediana; brácteas ovaladas ou cimbiformes. 
6. Lâmina foliar cordiforme ou ovalada; brácteas ovaladas ou orbiculares; frutos elipsóides ou subglobosos.....A. rufescens 6. Lâmina foliar elíptica ou suborbicular, brácteas deltóides ou cimbiformes; frutos oblongos ou botu liformes

A. grisebachii

7. Arbusto, venaçâo acródroma basal, estaminódios lanceolados; ovário glabro a pubescente apenas nas regiốes ventral e apical.

A. grandifolia

7. Liana, venação actinódroma suprabasal, estaminódios filiformes, clavados, falcados ou oblongos; ovário estrigoso, seríceo, tomentoso ou velutino.

.8

8. Ritidoma estriado; nervuras terciárias não evidentes na face adaxial; brácteas tomentosas; ovário obovóide.

A. imene

8. Ritidoma fissurado ou sulcado; nervuras terciárias superficiais ou inconspicuamente proeminentes na face adaxial; brácteas estrigosas, esparsamente pubérulas, seríceas ou velutinas; ovário ovóide, turbinado ou botuliforme.

9. Nervuras laterais principais nao oblíquas, antera com deiscência transversal.

A. velutina

9. Nervuras laterais principais oblíquas; antera com deiscência longitudinal.

10. Ápice foliar agudo ou acuminado; nervuras secundarias divergindo da regiáo mediana ou do terço superior laminar; estames totalmente conados em grupos de 3

A. brevifolia

10. Ápice foliar cuspidado ou atenuado; nervuras secundarias divergindo do terço inferior laminar; estames livres ou conados apenas no ponto de inserçáo basal..

A. solimoesensis

\section{Descrição das espécies de Abuta ocorrentes no estado do Pará}

Abuta barbata Miers, Contributions to botany, iconographic and descriptive 3: 83. 1871. Tipo: Guiana Francesa. Sagot 919 (G). Figura 1 A-D.

Liana lenhosa, 14-29 cm diâm., escandente ou não; ritidoma marrom a acinzentado, fissurado; alburno creme a alaranjado. Pecíolo 6,4-7,7 cm comprimento, 0,2-0,3 $\mathrm{cm}$ diâm., cilíndrico, viloso-ferrugíneo. Lâmina foliar 7,1$18,7 \mathrm{~cm}$ compr., $8,7-11,3 \mathrm{~cm}$ largura, elíptica à obovada, cartácea, discolor, levemente bulada, viloso-ferrugínea em ambas as faces; ápice obtuso, arredondado ou emarginado, apiculado; base inteira ou 2-lobada, obtusa ou emarginada; margem inteira, retilínea, ciliada. Venaçâo actinódroma basal, nervuras principais 3-palmatinérveas na base, impressas, 2-submarginais; nervuras secundárias divergindo do terço inferior laminar; nervuras terciárias escalariformes, levemente impressas. Inflorescências em panículas, multifloras, fasciculadas, axilares. Brácteas $2-5 \mathrm{~mm}$ compr., 0,5-1 mm larg., lanceoladas ou oblongas, tomentosas. Flores estaminadas esverdeadas à verde-acinzentadas; sépalas 6-7, dispostas em verticilos bisseriados, 0,5-2 $\mathrm{mm}$ compr., 0,25-1,8 $\mathrm{mm}$ larg.,

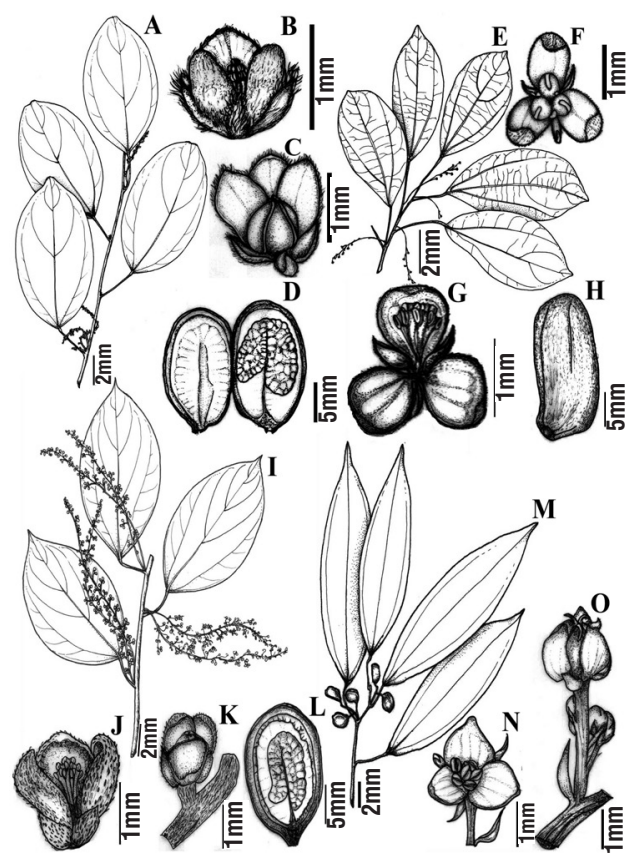

Figura 1. A-D Abuta barbata: A. ramo florido; B. flor estaminada; C. flor pistilada; D. fruto seccionado. E-H Abuta brevifolia: E. ramo florido; F. flor pistilada; G. flor estaminada; H. fruto. I-L Abuta candollei: I. ramo florido; J. flor estaminada; K. flor pistilada; L. fruto seccionado. M-0 Abuta grandifolia: M. ramo frutífero; N. flor estaminada; 0 . flor pistilada.

elípticas, ovaladas, obovadas ou oblongas, tomentosas; estames 6 , oblongos, clavados ou tortuosos, livres ou pelo menos dois conados, glabros; anteras com deiscência longitudinal. Flores pistiladas esverdeadas a amareladas; sépalas 6 , dispostas em verticilos bisseriados, 0,4-2 $\mathrm{mm}$ compr., 0,25-2 $\mathrm{mm}$ larg., elípticas, ovaladas, obovadas ou oblongas, tomentosas; estaminódios 6, 0,5-1,2 mm compr., filiformes, glabros; ovário 0,5-1,5 mm compr., séssil, giboso ou ovóide, glabrescente a piloso; estigma bífido, labiado, subapical, glabro a glabrescente. Frutos imaturos.

Material selecionado: Brasil. Pará: Marapanim, capoeira, 15.XII.2011, fr.ima., Sousa, J.S. 518 (MG); Remansão, rio Tocantins, 4.IX.1948, fl., Fróes, R. L. 23382 (IAN).

Material adicional: Brasil. Acre: serra da Malacachêta, VIII.1913, fl., Kulhmam, J. G. 455 (RB).

Distribuiçáo geográfica: A espécie ocorre na Guiana, Suriname, Guiana Francesa e Brasil: Acre e Pará (Braga 2012; Mobot 2012). O táxon pode ser encontrado em mata de terra firme, em solos argilosos ou areno-argilosos.

Abuta brevifolia Krukoff \& Moldenke, Bulletin of the Torrey Botanical Club 69: 160. 1942. Tipo: Brasil. Duckes.n (H.A.M.P. 8976). Figura 1 E-H.

Liana lenhosa até $18-32 \mathrm{~cm}$ diâm., escandente; ritidoma marrom a acinzentado, fissurado; alburno creme a alaranjado. 
Pecíolo 7-31 mm compr., 0,8-1,5 mm diâm., cilíndrico, pubescente a hirsuto. Lâmina foliar 2,3-7,8 cm compr., 1,5$4,5 \mathrm{~cm}$ larg., elíptica à ovalada, coriácea, levemente discolor, plana a levemente bulada, glabra a esparsamente pubescente na face adaxial, pubescente na abaxial; ápice agudo ou acuminado, apiculado; base inteira, cuneada a obtusa; margem inteira, repanda, náo ciliada ou apenas no terço inferior. Venaçáo actinódroma suprabasal, nervura principais 3-plinérveas na base, superficiais a inconspicuamente impressas e, quando presentes, 2 submarginais; nervuras secundárias divergindo da regiâo mediana ou do terço superior laminar; nervuras terciárias escalariformes, superficiais. Inflorescências em panículas, multifloras, fasciculadas, axilares ou supra-axilares. Brácteas 0,5-4 mm compr., 0,25-0,75 mm larg., deltóides ou ovaladas, densamente estrigosas. Flores estaminadas esverdeadas à amareladas; sépalas 6-7, em verticilos bisseriados, 0,5-1,8 mm compr., 0,2-1,4 mm larg., deltóides, elípticas, lanceoladas, orbiculares, ovaladas, obovadas ou oblongas, estrigosas; estames 6 , totalmente conados em grupos de 3 , clavados, glabros; anteras com deiscência longitudinal. Flores pistiladas esverdeadas a amarelo-esbranquiçadas; sépalas 6 , em verticilos bisseriados, $0,5-2 \mathrm{~mm}$ compr., $0,2-1,5 \mathrm{~mm}$ larg., lanceoladas, deltóides, elípticas, orbiculares, ovaladas, obovadas ou oblongas, estrigosas à tomentosa; estaminódios 6, 0,5-1,5 mm compr., filiformes, glabros; ovário 0,5-1,7 mm compr., séssil, ovóide, estrigoso; estigma inteiro, subapical, glabrescente. Frutos drupáceos, 1,6-2,4 cm compr., 1-1,3 $\mathrm{cm}$ diâm., oblongos, esverdeados, velutinos, ápice obtuso a arredondado; base obtusa ou assimétrica.

Material selecionado: Brasil. Pará: Moju, capoeira, 7.VII.2011, fl., Sousa, J.S. 515 (MG); Alto Tapajós, rio Cururú, 18.II.1974, fl., Anderson, W. R. 11075 (IAN); Belém, $9 \mathrm{~km}$ do Instituto Agronômico do Norte, 27.IX.1942, fr., Silva, M. B. 109 (IAN).

Distribuiçáo geográfica: A espécie distribui-se na Venezuela e no Brasil: Acre, Amazonas e Pará (Braga 2012; Mobot 2012). Na Amazônia brasileira, a espécie pode ser encontrada em diversos ambientes, preferencialmente em mata de terra firme, campinarana, capoeira, crescendo em solos argilosos ou arenosos.

Abuta candollei Triana \& Planch., Annales des Sciences Naturelles; Botanique, série 4 17: 47. 1862. Tipo: Guiana Francesa. Sagot s.n (P). Figura 1 I-L.

Liana lenhosa 17-25 diâm., escandente; ritidoma marrom a acinzentado, fissurado ou sulcado; alburno creme a alaranjado. Pecíolo 3-4,5 cm compr., 0,1-0,2 cm larg., cilíndrico ou canaliculado, tomentoso. Lâmina foliar 7,3-14,9 cm compr., 3,3-8,6 cm larg., elíptica ou suborbicular, subcoriácea, levemente discolor, plana, glabra a esparsamente pubescente na face adaxial, tomentosa na face abaxial; ápice agudo a acuminado, apiculado; base inteira ou inconspicuamente lobada, cuneada, obtusa ou subcordada; margem inteira, retilínea, não ciliada. Venação actinódroma basal, nervuras principais 3-palmatinérveas na base, superficiais a impressas; raro 2 submarginais; nervuras secundárias divergindo abaixo da regiāo mediana; nervuras terciárias imperceptíveis na face adaxial. Inflorescências em panículas, multifloras, fasciculadas, axilares ou supra-axilares. Brácteas 0,5-3 mm compr., 0,2-0,8 $\mathrm{mm}$ larg., lanceoladas ou espatuladas, tomentosas. Flores estaminadas verde-acinzentadas; sépalas 6 , dispostas em verticilos bisseriados, 0,7-2,4 $\mathrm{mm}$ compr., 0,5-1,8 $\mathrm{mm}$ larg., elípticas, cimbiformes, obovadas, orbiculares ou ovaladas, tomentosas; estames 6 , conados na base, formando um sinândrio, turbinados raro clavados, glabros; anteras com deiscência longitudinal. Flores pistiladas, verde-acinzentadas; sépalas 6 , dispostas em verticilos bisseriados, 0,5-2 mm compr., 0,5-2 mm larg., elípticas, obovadas, orbiculares, ovaladas ou cimbiformes, tomentosas; estaminódios 6, 0,5$1,5 \mathrm{~mm}$ compr., filiformes, glabrescentes; ovário $0,5-1,8 \mathrm{~mm}$ compr., séssil, ovóide à giboso, glabrescente a esparsamente tomentoso; estigma ausente. Frutos drupáceos, 1,4-2,1 cm compr., 1-1,4 cm diâm., oblongos ou elipsóides, esverdeados, tomentosos, ápice obtuso a arredondado; base cuneada, obtusa ou assimétrica.

Material selecionado: Brasil. Pará: Castanhal, várzea, 15.IV.2011, fr., Sousa, J.S. 508 (MG); Óbidus, mata, 30.VII.1902, fl., Ducke s.n. (MG); rio Univini, igarapé do campo, 24.VI.1974, fl., Pires, J.M. et al. 11075 (MG).

Distribuiçáo geográfica: A espécie está distribuída na Guiana Francesa, Suriname, Guiana, Venezuela, Bolívia e no Brasil: AP, AM, RR e PA (Braga 2012; Mobot 2012). Na área de estudo, a espécie ocorre em mata de terra firme e lugares alagados; em solos argilosos a arenosos.

Abuta grandifolia (Mart.) Sandwith, Bulletin of Miscellaneous Information Kew 1937: 397. 1937. Tipo de Cocculus grandifolius Mart.: Brasil. Martius s.n(Mu). Figura $1 \mathrm{M}-\mathrm{O}$.

Arbusto escandente 1,5-5 m.alt., $8-35 \mathrm{~cm}$ diâm.; ritidoma marrom ou acinzentado, fissurado; alburno amarelo-esbranquiçado a bege, com estrias alvas. Pecíolo 0,9-14,3 cm compr., 0,1-0,3 cm diâm., cilíndrico, glabro ou pubérulo. Lâmina foliar 7,7-55 cm compr., 2,9-15,1 cm larg., elíptica, elíptico-lanceolda, lanceolada, oblonga, oblanceolada ou obovada, cartácea a coriácea, discolor, plana, glabra em ambas as faces; ápice agudo, acuminado ou raro atenuado, apiculado; base inteira, não lobada, cuneada ou raro obtusa; margem inteira, retilínea, não ciliada. Venação acródroma basal, nervuras principais 3-palmatinérveas na base, proeminentes e, quando presentes, 2 submarginais; nervuras secundárias e terciárias numerosas, inconspícuas na face adaxial. Inflorescências em racemos ou panículas, multifloras, axilares ou supra-axilares, caulifloras. Brácteas 0,7-2,5 mm 
compr., 0,5-1 mm larg., lanceoladas, ovaladas ou deltóides, glabras. Flores estaminadas esverdeadas à amareladas; sépalas 6, em verticilos bisseriados, $0,5-2,5 \mathrm{~mm}$ compr., $0,2-1,8 \mathrm{~mm}$ larg., elípticas, lanceoladas ovaladas, orbiculares ou oblongas, pubérulas; estames 6 , livres ou em sinândrio, glabros; anteras com deiscência transversal. Flores pistiladas esverdeadas a amarelo-esbranquiçadas; sépalas 6 , em verticilos bisseriados, 0,5-2,8 mm compr., 0,2-2 mm larg., elípticas, lanceoladas, ovaladas, orbiculares ou oblongas, pubérulas; estaminódios 6, 0,8-1,5 mm compr., lanceolados, glabros; ovário 0,5-1,5 $\mathrm{mm}$ compr., séssil, ovoide ou giboso, glabro a pubescente nas regiôes ventral e apical; estigma inteiro, falciforme, subapical, pubescente. Frutos drupáceos, 1,5-3 cm compr., 1-1,5 cm diâm., ovóides, oblongos ou obovóides, amarelos, glabros ou pubescentes, ápice obtuso a arredondado; base obtusa ou assimétrica.

Material selecionado: Brasil. Pará: rio Curuá-Una, mata virgem da cachoeira do Portão, região do Planalto de Santarém, 14.XI.1954, fl., Fróes, R. L. 31403 (IAN); Belém, IPEAN, capoeira Black, 12.IV.1968, fl., Pires, J. M. 11711 (IAN); Marapanim, Vila de Santa Luzia, 17.II.2010, fr., Sousa, J. S. 293 (MG).

Distribuiçáo geográfica: A espécie distribui-se na Venezuela, Bolívia, Colômbia, Equador, Guiana, Guiana Francesa, Peru, Suriname e no Brasil: Acre, Amapá, Amazonas, Ceará, Goiás, Maranhão, Mato Grosso, Pará, Rondônia, Roraima e Tocantins (Braga 2012; Mobot 2012). De acordo com Revilla (2002), essa espécie pode ser encontrada em campina, igapó, bosque primário, áreas inundáveis altas, em capoeira, campos degradados e capinzais; em condiçóes de intensidade luminosa moderada, crescendo sobre solos semilateríticos a lateríticos.

Abuta grisebachii Triana \& Planch., Annales des Sciences Naturelles IV, 17: 47. 1862. Tipo: Brasil. Spruce 2340 (B). Figura $2 \mathrm{~A}-\mathrm{D}$.

Liana lenhosa 7-35 cm diâm., escandente; ritidoma marrom-escuro a acinzentado; alburno creme-alaranjado. Pecíolo 0,5-7,9 cm compr., 0,1-0,2 cm diâm., cilíndrico, não canaliculado, tomentoso a seríceo. Lâmina foliar 2,9-14,8 cm compr., 1,8-8,4 cm larg., ovalada, elíptica ou suborbicular, coriácea, fortemente discolor, plana, pubescente a tomentosa nas nervuras principais na face adaxial, cinéreo-tomentosa na abaxial; ápice agudo, acuminado ou atenuado, apiculado ou não; base inteira, obtusa ou raro cuneada; margem inteira, retilínea, adpressamente ciliada. Venaçáo actinódroma basal, nervuras principais 5-palmatinérveas na base, superficiais a impressas; nervuras secundárias divergindo da regiâo mediana; nervuras terciárias escalariformes, superficiais ou impressas. Inflorescências em panículas ou racemos, multifloras, axilares ou supra-axilares, caulifloras. Brácteas 0,7-2,5 mm compr., 0,3-0,9 mm larg., deltóides ou cimbiformes, tomentosas.
Flores estaminadas esverdeadas a ferrugíneas; sépalas 6 , dispostas em verticilos bisseriados, 0,7-1,8 mm compr., 0,4$1,5 \mathrm{~mm}$ larg., cimbiformes, elípticas, obovadas, ovaladas ou orbiculares, tomentosas; estames 6 , parcialmente ou totalmente conados formando um sinândrio, claviformes, turbinados ou oblongos, glabros; anteras com deiscência longitudinal. Flores pistiladas esverdeadas; sépalas 6 , em verticilos bisseriados, 0,5-2 mm compr., 0,3-1,6 mm larg., cimbiformes, elípticas, obovadas, ovaladas ou orbiculares, tomentosas; estaminódios 6, 0,8-1,6 mm compr., filiformes, pubescentes; ovário 0,5-1,8 $\mathrm{mm}$ compr., séssil, ovóide a turbinado, tomentoso; estigma bífido, ligulado, subapical, glabro a glabrescente. Frutos drupáceos 1,2-2,2 cm compr., 1,1-1,8 cm diâm., oblongos ou botuliformes, cinéreo-esverdeados, tomentosos, ápice obtuso a arredondado; base cuneada, obtusa ou assimétrica.

Material selecionado: Brasil. Pará: rio Xingu, 29.XI.1955, fl., Fróes, R.L. 32451 (IAN); Alto Tapajós, Vila Nova, perto da cachoeira do Chacorão, 21.I.1952, fl., Pires, J. M. 3981 (INPA); Castanhal, várzea, 15.IV.2011, fr., Sousa, J.S. 509 (MG).

Distribuição geográfica: A espécie distribui-se na Venezuela, Colômbia, Peru e no Brasil: ocorrendo nos estados do Amazonas, Mato Grosso, Pará e Roraima (Braga 2012; Mobot 2012). Trata-se de uma espécie frequente na Amazônia brasileira, que pode ocorrer em mata de terra firme, sendo muito comum em áreas alagadas como várzea, em solos

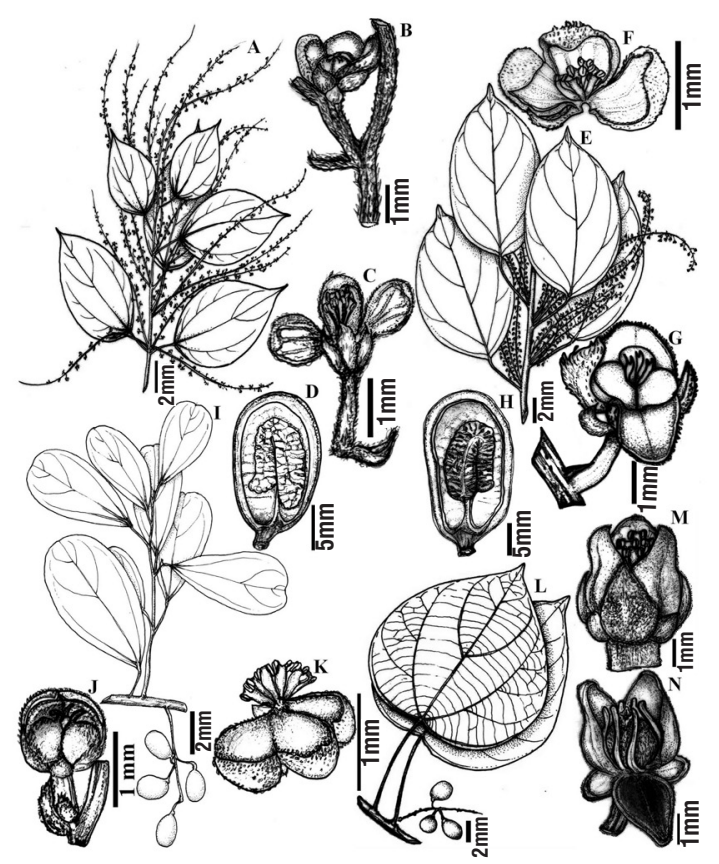

Figura 2. A-D Abuta grisebachii: A. ramo florido; B. flor pistilada; C. flor estaminada; D. fruto seccionado. E-H Abuta imene: E. ramo florido; F. flor estaminada; G. flor pistilada; H. fruto seccionado. I-K Abuta obovata: I. ramo frutífero; J. flor pistilada; K. flor estaminada. L-N Abuta rufescens: L. ramo frutifero; M. flor estaminada; N. flor pistilada. 
argilosos ou areno-argilosos. De acordo com Sothers et al. (1999), esta espécie ocorre nas formaçóes vegetais de platô, baixio e campinarana.

Abuta imene (Mart.) Eichler, Flora 47: 389. 1864. Tipo: Brasil. Spruce s.n. (B). Figura 2 E-H.

Liana lenhosa 19-35 cm diâm., escandente; ritidoma marrom a acinzentado, estriado; alburno creme a alaranjada. Pecíolo 1,5-5,9 cm compr., 0,1-0,2 cm diâm., cilíndrico, glabro a esparsamente pubescente. Lâmina foliar $5,5-15 \mathrm{~cm}$ compr., 3,2-10,4 cm larg., elíptica, ovalada, oblanceolada ou suborbicular, subcoriácea a coriácea, concolor a levemente discolor, plana, glabra em ambas as faces; ápice acuminado a atenuado, apiculado; base inteira, cuneada, obtusa, arredondada ou raramente truncada; margem inteira, retilínea, não ciliada ou apenas no terço inferior. Venação actinódroma supra-basal, nervuras principais 3-plinérveas na base, superficiais a ligeiramente proeminentes e, quando presentes, 2 submarginais; nervuras secundárias divergindo da região mediana; nervuras terciárias escalariformes não evidentes na face adaxial. Inflorescências em panículas, multifloras, axilares ou supra-axilares, caulifloras. Brácteas 0,7-1,2 mm compr., 0,5-0,8 mm larg., cimbiformes ou deldóides, tomentosas. Flores estaminadas esverdeadas; sépalas 6 , dispostas em verticilos bisseriados, 0,5-1,4 mm compr., 0,3-1 mm larg., cimbiformes, elípticas, deltóides, ovaladas, obovadas ou orbiculares, tomentosas; estames 6 , totalmente ou parcialmente conados formando um sinândrio, dispostos de forma triangular, ou às vezes dois estames livres, clavados, glabros; anteras com deiscência longitudinal. Flores pistiladas, esverdeadas; sépalas 6, dispostas em verticilos bisseriados, 0,5-1,5 mm compr., 0,25-1,1 mm larg., livres, cimbiformes, deltoides, elípticas, obovadas ou orbiculares, tomentosas; estaminódios 6, 0,8-1,6 mm compr., filiformes, esparsamente pubescente; ovário $0,5-1,8 \mathrm{~mm}$ compr., séssil, obovóide, tomentoso; estigma bífido, ligulado, subapical, glabescente a tomentoso. Frutos drupáceos, 1-2,4 cm compr., 0,7-1,5 cm diâm., oblongos ou elipsóides, esverdeados ou castanhos, glabros ou raro pubescente na base, ápice obtuso a arredondado, base cuneada, obtusa ou assimétrica.

Material selecionado: Brasil. Pará: Região do rio CuruáUna, Baixo Amazonas, mata de terra firme, VI.1957, fr., Fróes, R. L. 33892 (IAN); rio Jamundá, 15.V.1911, fl., Ducke, A. 11723 (RB); Santarém Novo, várzea, 15.IV.2011, fl.\& fr., Sousa, J.S. 511 (MG).

Distribuição geográfica: $\mathrm{A}$ espécie distribui-se na Venezuela, Bolívia, Colômbia, Equador, Guiana, Guiana Francesa, Peru, Suriname e no Brasil: Amazonas, Mato Grosso, Pará e Rondônia (Braga 2012; Mobot 2012). Trata-se de uma espécie rara na Amazônia brasileira, que pode ocorrer em mata de terra firme, sendo mais comum em áreas alagadas como várzea, em solos argilosos. De acordo com Sothers et al. (1999), esta espécie ocorre nas formaçôes vegetais de baixio e vertente.

Abuta obovata Diels, Notizblatt des Botanischen Gartens und Museums zu Berlin-Dahlem 13: 20. 1936. Tipo: Guiana. de la Cruz 2250 (F, NY). Figura 2 I-K.

Liana lenhosa até ca. $35 \mathrm{~cm}$ diâm., escandente ou não; ritidoma marrom a acinzentado; alburno creme a alaranjado. Pecíolo 0,8-2,8 cm compr., 0,8-1,5 mm diâm., cilíndrico, pubescente. Lâmina foliar 3,7-9,3 cm compr., 2,2-7 cm larg., obovada, coriácea, concolor à ligeiramente discolor, profundamente bulada, pubescente somente na nervura principal na face adaxial, pubescente na abaxial; ápice obtuso, arredondado ou levemente emarginado, apiculado; base inteira, não lobada, cuneada, obtusa ou assimétrica; margem inteira, retilínea a levemente repanda, ciliada ou não. Venação actinódroma basal; nervuras principais 3-palmatinérveas na base, conspicuamente impressas e, quando presentes, 2 submarginais; nervuras secundárias divergindo da região mediana; nervuras terciárias escalariformes, superficiais a proeminentes. Inflorescências em panículas, multifloras, axilares ou supraaxilares. Brácteas 0,5-1 mm compr., 0,4-0,8 mm larg., ovaladas ou cimbiformes, tomentosas. Flores estaminadas, esverdeadas; sépalas 6-9, em verticilos trisseriados, 0,3-1,2 $\mathrm{mm}$ compr., 0,25-1,2 mm larg., elípticas, ovaladas obovadas, orbiculares ou cimbiformes, tomentosas; estames 6 , parcialmente conados ou apenas no ponto de inserção basal, formando um sinândrio de forma triangular ou obcônica, dolabriformes a turbinados, glabros; anteras com deiscência longitudinal. Flores pistiladas esverdeadas; sépalas 6-9, em verticilos trisseriados, 0,4-1,5 mm compr., 0,25-1,4 mm larg., cimbiformes, deltóides, obovadas ou orbiculares, tomentosas; estaminódios 6, 0,9$1,7 \mathrm{~mm}$ compr., filiformes, glabros a pubescentes na base; ovário 1,2-2,2 mm compr., séssil, ovóide a giboso, tomentoso, unilocular; estigma bífido, labiado, subapical, tomentoso. Frutos drupáceos, 1,3-2 cm compr., 0,6-1,4 cm diâm., oblongos ou obovóides, esverdeados, tomentosos, ápice obtuso a arredondado; base cuneada, obtusa ou assimétrica.

Material selecionado: Brasil. Pará: Município de Oriximiná, Estação Ecológica Grāo Pará, 28.VIII.2008, fl., Maciel, S. \& Pietrobom, M. 821 (MG); Barcarena, capoeira, 14.IV.2011, fl. \& fr., Sousa, J.S. 507 (MG).

Material adicional: Brasil. Amazonas: Município de Borba, Rio Madeira, afluente do Rio Amazonas, mata de terra firme, 24.VI.1983, fl., Cid, C.A. 3924 (INPA).

Distribuiçáo geográfica: A espécie distribui-se na Venezuela, Guiana, Guiana Francesa, Peru, Suriname e no Brasil: Acre, Amapá e Amazonas (Braga 2012; Mobot 2012). Também foi registrada pela primeira vez, através desse estudo, no estado do Pará. Trata-se de uma espécie rara na Amazônia brasileira, que pode ocorrer em floresta de terra firme, em mata ciliar e áreas alteradas, em solos areno-argilosos. De 
acordo com Sothers et al. (1999), esta espécie também pode ser encontrada em campinarana.

Abuta rufescens Aubl., Histoire des Plantes de la Guiane Françoise 1: 618-620, t. 250. 1775. Tipo: Guiana Francesa. Aublet s.n. (holótipo BM). Figura 2 L-N.

Liana lenhosa até 19-30 cm diâm., escandente; ritidoma marrom a acinzentado, fissurado ou sulcado; alburno creme a alaranjado. Pecíolo 1-20,6 cm compr., 0,1-0,3 cm diâm., cilíndrico, tomentoso. Lâmina foliar 4,3-24,9 cm compr., 3,5-24,9 cm larg., cordiforme ou ovalada, cartácea a coriácea, fortemente discolor, levemente bulada, pubescente a tomentosa somente nas nervuras na face adaxial, cinéreo-tomentosa na abaxial; ápice agudo, acuminado ou atenuado, apiculado; base inteira ou bilobada, arredondada, truncada, emarginada ou cordada; margem inteira, repanda ou retilínea, ciliada. Venação actinódroma basal; nervuras principais 5-palmatinérveas, impressas; nervuras secundárias divergindo da regiáo mediana ou do terço superior na nervura central; nervuras terciárias escalariformes, impressas. Inflorescências em racemos ou panículas, multifloras, axilares e/ou supra-axilares. Brácteas 0,7-1,5 mm compr., 0,7-1,1 mm larg., ovaladas ou orbiculares, velutinas. Flores estaminadas cinéreo-esverdeadas, sépalas 6-9, em verticilos trisseriados, 0,6-4,2 $\mathrm{mm}$ compr., 0,6-4 $\mathrm{mm}$ larg., obovadas ovaladas ou orbiculares, velutinas; estames 6 , livres ou conados apenas no ponto de inserção basal, formando um sinândrio, lineares ou oblongos, às vezes pelo menos dois clavados, inconspicuamente papilosos; anteras com deiscência longitudinal. Flores pistiladas cinéreo-esverdeadas, sépalas 6-9, em verticilos trisseriados, 0,5-4,5 mm compr., 0,5$4,2 \mathrm{~mm}$ larg., deltóides, elípticas, ovaladas ou orbiculares, velutinas; estaminódios 6, 2-3,2 $\mathrm{mm}$ compr., filiformes ou falciformes, retorcidos, pubescente na regiáo dorsal e na base; ovário 1,2-3 mm compr., séssil, súpero, ovóide a turbinado, velutino; estigma bífido, labiado, subapical, tomentoso. Frutos drupáceos, 1,8-2,4 cm compr., 1,5-1,8 cm diâm., elipsóides ou subglobosos, cinéreo-esverdeados, estriados, velutinotomentosos, ápice obtuso a arredondado, base cuneada, obtusa ou assimétrica.

Material selecionado: Brasil. Pará: Serra dos Carajás, 13 $\mathrm{km}$ de AMZA, floresta de terra firme, 17.X.1977, fl., Silva, A.S. et al. 58 (INPA); Regiáo do Jarí, Monte Dourado, mata de terra firme, 21.X.1968., fl., Silva, N. T. 1282 (IAN); Regiáo do Jarí, Santa Patrícia, mata de terra firme, 9.V.1970, fr., Silva, N. T.3125 (IAN).

Distribuiçáo geográfica: A espécie distribui-se na Venezuela, Colômbia, Equador, Guiana, Guiana Francesa, Peru, Suriname e no Brasil: Acre, Amapá, Amazonas, Pará, Rondônia, Tocantins (Braga 2012; Mobot 2012). É frequente na Amazônia brasileira, ocorrendo em floresta de terra firme, igapó, mata ciliar, caatinga, áreas alteradas, em solos argilosos, arenosos ou areno-argilosos. Segundo Sothers et al. (1999), a espécie também pode ocorrer em platô, vertente e baixio.

Abuta sandwithiana Krukoff \& Barneby, Memoirs of the New York Botanical Garden 20(2): 18. 1970. Tipo: Brasil. Pires 3693 (NY). Figura 3 A-C.

Arbusto $1-5 \mathrm{~m}$ alt., $38 \mathrm{~cm}$ diâm., ritidoma marrom a acinzentado, fissurado; alburno amarelo-escuro. Pecíolo 0,7-5,2 cm compr., 0,1-0,15 cm diâm., cilíndrico, estrigoso. Lâmina foliar 7,5-21 cm compr., 2,5-8,5 cm larg., elíptica, obovada ou oblongo-lanceolada, cartácea, concolor, acentuadamente bulada, glabra a esparsamente pubescente na face adaxial e pubescente à híspida na abaxial; ápice acuminado a longo-atenuado, inconspicuamente apiculado; base inteira, cuneada ou obtusa; margem inteira, retilínea ou levemente repanda, não ciliada. Venação actinódroma basal, nervuras principais 3-pseudopalmatinérveas, profundamente impressas; nervuras secundárias geralmente divergindo da região mediana; nervuras terciárias irregularmente escalariformes, profundamente impressas na face adaxial. Inflorescências em panículas ou racemos, multifloras, axilares. Brácteas 1-2 mm compr., 0,6-1 mm larg., deltóides, lanceoladas, estreito-triangulares ou falcadas, estrigosas ou hirsutas. Flores estaminadas esverdeadas; sépalas 6-7, dispostas em verticilos bisseriados, 0,5-2,5 mm compr., 0,2-2 mm larg., cimbiformes, deltoides, elípticas, oblanceoladas, obovadas, oblongas ou orbiculares, seríceas ou estrigosas; estames 6, livres ou conados apenas no ponto de inserção basal, obclavados, oblanceolados ou fusiformes, glabros; anteras com deiscência longitudinal. Flores pistiladas esverdeadas; sépalas 6-7, dispostas em verticilos bisseriados, 0,5-2 mm compr., 0,2-2,2 mm larg., deltóides, elípticas, oblanceoladas, obovadas, oblongas, ovaladas ou orbiculares, estrigosas ou seríceas; estaminódios 6, 0,4-2,2 mm compr., lineares ou oblongos, glabros a pubescentes na região dorsal e/ou na base; ovário 0,3-2 mm compr., séssil, ovóide, turbinado ou botuliforme, seríceo; estigma caduco. Frutos drupáceos, 1,42,5 cm compr., 0,8-1,4 cm diâm., subglobosos, oblongos ou elipsóides, esverdeados, seríceos ou velutinos, ápice obtuso a arredondado; base cuneada, obtusa ou assimétrica.

Material selecionado: Brasil. Pará: município de Oriximiná, Rio Mapuera, margem direita entre a cachoeira da Madame, mata alagável, 15.VIII.1986, fl., Ferreira, C. A. et al. 7776 (RR); município de Oriximiná, 200m da margem da estrada da Cachoeira Porteira, km 24, mata de terra firme, 20.VI.1980, fr., Cid, C. A. \& Ramos, J. 1104 (INPA); Mosqueiro, 11.IX.2011, fr., Sousa, J. S. 516 (MG).

Distribuição geográfica: A espécie distribui-se na Bolívia, Guiana, Guiana Francesa, Peru, Suriname e no Brasil: Acre, Amapá, Amazonas, Mato Grosso, Pará e Rondônia (Braga 2012; Mobot 2012). Trata-se de uma espécie rara no estado do Pará, podendo ocorrer em floresta de terra firme e áreas 


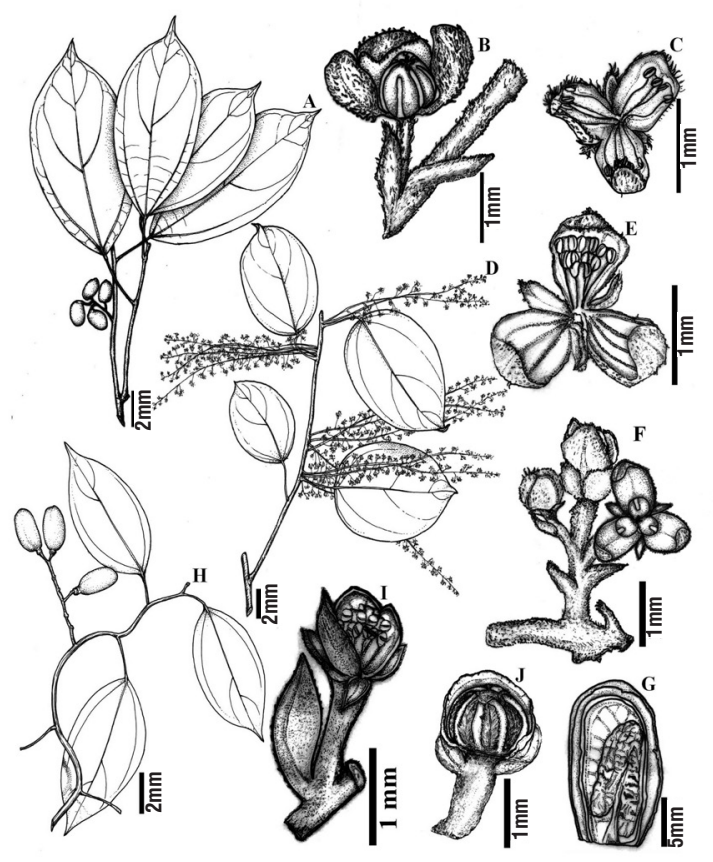

Figura 3. A-C Abuta sandwithiana: A. ramo frutífero; B. flor pistilada; C. flor estaminada. D-G Abuta solimoesensis: D. ramo florido; E. flor estaminada; $F$. flores pistiladas; G. fruto seccionado. H-J Abuta velutina: H ramo frutífero; I. flor estaminada; J. flor pistilada.

inundáveis, em solos argilosos ou areno-argilosos. De acordo com Sothers et al. (1999), a espécie também pode ser encontrada em vertente e baixio.

Abuta solimoesensis Krukoff \& Barneby, Memoirs of the New York Botanical Garden 20(2): 18. 1970. Tipo: Brasil. Froes 23964 (NY). Figura 3 D-G.

Liana lenhosa 21-32 cm diâm., escandente; ritidoma marrom a acinzentado, fissurado ou sulcado; alburno creme a alaranjado. Pecíolo 2,7-7,9 cm compr., 0,1-0,25 cm diâm., cilíndrico, glabro a raro esparsamente pubescente. Lâmina foliar 7,1-21 cm compr., 4,5-13,1 cm larg., ovalada a elíptica, cartácea ou coriácea, concolor ou levemente discolor, plana, glabra em ambas as faces; ápice cuspidado ou atenuado, apiculado; base inteira, obtusa à arredondada ou raro subtruncada; margem inteira, retilínea, não ciliada. Venação actinódroma suprabasal, nervuras principais 3-plinérveas na base, subimpressas e, quando presente, 2 submarginais; nervuras secundárias divergindo do terço inferior; nervuras terciárias irregularmente escalariformes, superficiais. Inflorescências em panículas, multifloras, axilares ou supra-axilares. Brácteas $0,5-1,5 \mathrm{~mm}$ compr., 0,2-0,8 mm larg., deltóides ou lanceoladas, estrigosas ou seríceas. Flores estaminadas esverdeadas; sépalas 6-9, dispostas em verticilos tisseriados, 0,25-1,5 mm compr., 0,2-1 mm larg., livres, cimbiformes, deltoides, elípticas, lanceoladas, obovadas, ovaladas ou orbiculares, estrigosas; estames 6 , livres ou conados apenas no ponto de inserção basal, clavados, glabros a esparsamente pubescentes; anteras dorsifixas, com deiscência longitudinal. Flores pistiladas esverdeadas; sépalas 6-9, dispostas em verticilos bisseriados, 0,2-2 $\mathrm{mm}$ compr., 0,21,8 mm larg., cimbiformes, lanceoladas, deltoides, oblongas, obovadas, orbiculares ou ovaladas, estrigosas; estaminódios 6 , 0,8-1,6 mm compr., lineares, clavados ou falciformes, glabros a pubescente na regiáo basal; ovário $0,6-1,4 \mathrm{~mm}$ compr., séssil, ovóide, turbinado ou botuliforme, seríceo a tomentoso; estigma ausente. Frutos drupáceos, 1,5-2,4 cm compr., 0,6-1,4 cm larg., oblongos, castanhos-escuros, glabros, ápice obtuso a arredondado; base cuneada, obtusa ou assimétrica.

Material selecionado: Brasil. Pará: regiáo do Rio Jarí, estrada de Munguba, km 4, mata de terra firme, 18.IV.1969, fr., Silva, N.T.1872 (IAN); Belém, IPEAN, estrada do Cafezal, capoeira, 28.III.1968, fl., Silva, N.T.842 (IAN); Castanhal, capoeira, 15.IV.2011, fl., Sousa, J.S. 510 (MG).

Distribuição geográfica: a espécie distribui-se no Equador, Guiana Francesa, Peru e no Brasil: Acre, Amazonas e Pará (Braga 2012; Mobot 2012). Trata-se de uma espécie rara, podendo ocorrer em floresta de terra firme e áreas inundáveis, principalmente em várzeas, em solos argilosos ou arenoargilosos. De acordo com Ortiz (1997), esta espécie também pode ser encontrada em bosque primário.

Abuta velutina Gleason, Bulletin of the Torrey Botanical Club 58: 361. 1931. Tipo: Venezuela. Tate 959 (K, NY). Figura $3 \mathrm{H}-\mathrm{J}$.

Liana lenhosa 20-36 cm diâm., escandente ou não; ritidoma marrom a acinzentado, fissurado; alburno creme a alaranjado. Pecíolo 2-4,2 cm compr., 0,1-0,2 cm diâm., cilíndrico, velutino. Lâmina foliar 7,1-21 cm compr., 4,513,1 cm larg., elíptica, ovalada ou suborbicular, cartácea a subcoriácea, concolor a levemente discolor, plana, glabra na face adaxial, pubérula na abaxial; ápice atenuado a cuspidado, apiculado; base inteira, obtusa a arredondada ou acuminada; margem inteira, retilínea, não ciliada. Venação actinódroma suprabasal, nervuras principais 3-plinérveas na base, superficiais a levemente impressas e, quando presentes, 2 submarginais; nervuras secundárias divergindo do terço superior ou raro da regiáo mediana da lâmina; nervuras terciárias irregularmente escalariformes, superficiais ou proeminentes. Inflorescências em panículas, multifloras, axilares ou supra-axilares. Brácteas $0,5-1,8 \mathrm{~mm}$ compr., 0,2$0,9 \mathrm{~mm}$ larg., cimbiformes, deltóides ou lanceoladas, velutinas. Flores estaminadas esverdeadas; sépalas 6-9, dispostas em verticilos trisseriados, 0,3-1,2 mm compr., 0,2-1,2 mm larg., elípticas, ovaladas, lanceoladas ou cimbiformes, velutinas; estames 6, livres ou conados apenas no ponto de inserção basal, clavados ou dolabriformes, glabros a papilosos; anteras com deiscência transversal. Flores pistiladas esverdeadas, actinomorfas; sépalas 6-9, dispostas em verticilos bisseriados, 0,2-1,5 mm compr., 0,2-1,4 mm larg., cimbiformes, deltóides, 
elípticas, lanceoladas, obovadas, orbiculares ou ovaladas, velutinas ou estrigosas; estaminódios 6, 0,6-1,5 mm compr., lineares ou oblongos, esparsamente velutino na regiáo dorsal e basal; ovário 0,5-1,2 mm compr., séssil, ovóide ou turbinado, velutino; estigma bífido, labiado, glabro a estrigoso. Frutos drupáceos, 1,7-2,6 cm compr., 0,8-1,6 cm diâm., elipsóides ou oblongos, esverdeados, velutinos, ápice obtuso a arredondado, base cuneada, obtusa ou assimétrica.

Material selecionado: Brasil. Pará: BR 230, Transamazônica, $90 \mathrm{Km}$ de Itaituba, em floresta de terra firme, 29.XI.1977, fl., Prance, G. T. et al. P25842 (MG).

Material adicional: Brasil. Mato Grosso: Município Sinop, fazenda atlântica, floresta de terra firme, 25.IX.1985, fl., Thomas, Wet al. 4043 (SPF). Amazonas: estrada ManausItacoatiara, Km 156, floresta de terra firme, 6.VI.1973, fr., Rodrigues, Wet al. 9098 (INPA).

Distribuiçáo geográfica: A espécie distribui-se na Venezuela, Equador, Peru e no Brasil: Amazonas e Rondônia (Mobot 2012; Barneby 2001), constituindo uma nova ocorrência para o estado do Pará. Trata-se de uma espécie rara na Amazônia brasileira, ocorrendo em floresta de terra firme, em solos argilosos ou arenosos.

\section{DISCUSSÃO}

Entre os táxons do gênero Abuta ocorrentes do estado do Pará, A. barbata é facilmente distinta das demais, principalmente por suas folhas 3-palmatinérveas com tricomas viloso-ferrugíneos. Quando no estado de planta jovem, suas formas foliares assemelham-se com as de A. brevifolia, porém os tricomas viloso-ferrugíneos associado a venação actinódroma basal os distingui desta.

Por outro lado, $A$. brevifolia está intimamente relacionada com $A$. obovata, pois suas inflorescências são bastante semelhantes e geram dúvidas. Entretanto, nas amostras analisadas, pode-se diferenciá-las seguramente pela forma da folha e pelo padrão de venaçáo, uma vez que em $A$. brevifolia a lâmina foliar é de elíptica a ovalada e a venação actinódroma suprabasal (3-plinérveas), enquanto em $A$. obovata a lâmina foliar é obovada e a venação actinódroma basal (3-palmatinérveas).

Das espécies analisadas na área, é evidente a confusão entre $A$. candollei e $A$. grisebachii, entretanto a primeira espécie difere-se da última pela lâmina foliar levemente discolor, tomentosa na face abaxial e nervuras principais 3-palmatinérveas, enquanto que $A$. grisebachii possui lâmina foliar fortemente discolor, cinéreo-tomentosa na face abaxial e nervuras principais 5-palmatinérveas. Abuta grisebachii também é bastante confundida com $A$. rufescens, no entanto esta espécie pode ser facilmente distinta de $A$. grisebachii, quando as amostras apresentam folhas cordiformes e base cordada, entretanto, quando a folha é ovalada, o conjunto de caracteres formado pelos estames papilosos e o fruto subgloboso ajudam na separação das mesmas.

Entre as espécies do gênero Abuta, $A$. grandifolia é a mais comum e conhecida. Na Amazônia brasileira é confundida com A. panurensis pela semelhança das folhas, da qual se diferencia, vegetativamente, por ser um arbusto escandente com nervuras principais 3-palmatinérveas (venação acródroma basal), enquanto $A$. panurensis é uma liana lenhosa com nervuras principais 3-plinérveas (venação acródroma suprabasal). Abuta grandifolia também pode ser facilmente identificada por apresentar anteras com deiscência transversal, estaminódios lanceolados e estigma inteiro, falciforme, diferindo-se de $A$. panurensis que possui anteras com deiscência longitudinal, estaminódios filiformes ou oblongos e estigma bífido, labiado.

Nos acervos da região Norte, vários espécimes de $A$. imene estavam determinados como A. solimoesensis, devido à semelhança vegetativa, contudo, $A$. imene apresenta ritidoma longitudinalmente estriado, estames totalmente ou parcialmente conados e ovário obovoide, contrastando $\operatorname{com} A$. solimoesensis que possui ritidoma longitudinalmente fissurado ou sulcado, estames livres ou conados apenas no ponto de inserção e ovário ovoide, turbinado ou botuliforme.

Se no aspecto vegetativo, $A$. solimoesensis assemelha-se à $A$. imene, reprodutivamente pode ser confundida com $A$. velutina, da qual difere por apresentar nervuras principais laterais oblíquas, nervuras secundárias divergindo do terço inferior da lâmina, anteras com deiscência longitudinal e frutos glabros, enquanto $A$. velutina possui nervuras principais laterais não oblíquas, nervuras secundárias divergindo do terço superior ou raro da regiáo mediana da lâmina, anteras com deiscência transversal e frutos velutinos. Contrastando com as demais cogenéricas aqui tratadas, $A$. sandwithiana é facilmente identificada por ser um arbusto com alburno amarelo-escuro e nervuras terciárias buladas na face adaxial.

Diante disso, pode-se inferir que a venação foliar foi o principal caractere utilizado para a separaçáo das espécies de Abuta e a formaçáo de capoeira o ecossistema que apresentou o maior número de espécies, das quais Abuta obovata e $A$. velutina constituem novas ocorrências para o estado do Pará.

\section{AGRADECIMENTOS}

Os autores agradecem ao programa de pós-graduação (doutorado) da Rede de Biodiversidade e Biotecnologia da Amazônia Legal (PPG - BIONORTE), ao Museu Paraense Emílio Goeldi (MPEG) e ao Conselho Nacional de Desenvolvimento Científico e Tecnológico (CNPq) pela concessão da bolsa e apoio logístico para a realização deste trabalho. 


\section{BIBLIOGRAFIA CITADA}

Albuquerque, B.W.P. 1972. Contribuição ao estudo da nervação foliar de plantas da flora amazônica. Acta Amazonica, 2: 21 - 28.

Barneby, R.C. 2001. Menispermaceae, p. 554-578. In: Berry, P.; Holst, B.; Yatskievych, K. Flora of the Venezuelan Guayana: Liliaceae-Myrsinaceae. v.6. Missouri Botanical Garden Press, St. Louis, Missouri, USA.

Braga, J.M.A., 2012. Menispermaceae In: Lista de Espécies da Flora do Brasil, (http://floradobrasil.jbrj.gov.br/2011/FB010018). Acesso em 03/02/2012.

Di Stasi, L.C.; Hiruma-Lima, C.A. 2002. Plantas medicinais na Amazônia e na mata Atlântica. UNESP, São Paulo. 64p.

Fidalgo, O.; Bononi, V.L.R. 1984. Técnicas de coleta, preservação e herborização do material botânico. Instituto de Botânica, São Paulo. 62p.

Forzza, R.C. et al. 2010. Catálogo de plantas e fungos do Brasil. Instituto de Pesquisa do Jardim Botânico do Rio de Janeiro, Rio de Janeiro. 1699p.

Gonçalves, E.G.; Lorenzi, H. 2007. Morfologia vegetal: organografia e dicionário ilustrado de morfologia das plantas vasculares. Instituto Plantarum de Estudos da Flora, São Paulo. 446p.

Hickey, L.J. 1973. Classification of the arquitecture of dicotyledonous leaves. Americanjournal of Botany, 60: 17-33.

Hoot, S.B.; Zautke, H., Harris, D.J., Crane, P.R., Neves, S.S. 2009. Phylogenetic Patterns in Menispermaceae Based on Multiple Chloroplast Sequence Data. Systematic Botany, 34: 44-56.
Krukoff, B.A. 1982. Supplementary notes on American Menispermaceae XVII: Neotropical Triclisieae and Anomospermeae. Phytologia, 50: 80-111.

MOBOT, 2012. Missouri Botanical Garden, (http://www.mobot. org/W3T/Search). Acesso em: 02/01/2012.

Ortiz, R. 1997. Menispermaceae, p. 487-500. In: Vásquez, M.R., Flora de las Reservas Biológicas de Iquitos, Peru: Monographs in Systematic Botany from the Missouri Botanical Garden. v.63. Missouri Botanical Garden Press, St. Louis, USA.

Ortiz, R.D.C.; Kellogg, E.A.; Van Der Werff, H. 2007. Molecular phylogeny of the moonseed family (Menispermaceae): Implications for morphological diversification. American Journal of Botany, 94: 1425 - 1438.

Revilla, J. 2002. Plantas úteis da bacia amazônica. SEBRAE, INPA, Manaus. 445p.

Rizzini, C.T. 1977. Sistematização terminológica da folha. Rodriguésia, 29: 103-125. Sothers, C.A.; Brito, J.M.; OrtizGentry, R.; Ott, C. 1999. Menispermaceae, p. 190-193. In: Ribeiro, J.E.L.S. et al. Flora da Reserva Ducke: Guia de identificação das plantas vasculares de uma floresta de terra-firme na Amazônia central. Instituto Nacional de Pesquisas da Amazônia, Manaus, Amazonas.

Thiers, B. 2012. Index Herbariorum: a global directory of public herbaria and associated staff. New York Botanical Gardens Virtual Herbarium, (http://sweetgum.nybg.org/ih). Acesso em: 04/03/2012.

Recebido em 03/12/2012

Aceito em 14/06/2013 